Special Issue: Social Cognition and Self. Citation: Taiwo, J. (2015). Relationship between self-efficacy, problem-focused coping and performance. Behavioural Sciences Undergraduate Journal, 2(1), 37-41.

Author: Jeremiah Taiwo, Psychology, Mount Royal University (MRU)

Correspondence: jtaiw494@yahoo.co.uk

Reviewers: Christina Campbell, MRU; Kyle Gardiner, University of Calgary; Nancy Ogden, MRU; Serena Navarro, MRU

Editor: Famira Racy, MRU

Acknowledgements: The BSUJ thanks Dr. Dave Mumby from Concordia University for Associate Editorial contribution and Dr. Alain Morin for Guest Editorial research guidance.

Author Acknowledgements: I thank family and friends that encouraged and supported me in every way. I appreciate Dr. Alain Morin for guidance and insight on the paper and the Editor, Famira Racy, for her hard work and commitment to this project. And most importantly I thank God almighty for the strength and wisdom to see this through.

Copyright: (C) 2015 Jeremiah Taiwo. This is an open-access article distributed under the terms of the Creative Commons Attribution 4.0 International License. The use, distribution or reproduction of this article in other forums is permitted, provided the original author(s) or licensor are credited, a link to the licence is provided (CC for 4.0), it is indicated whether or not changes were made to the original article, and other conditions of the BSUJ and the other forums are met.

\title{
A Commentary on the Relationship between Self-efficacy, Problem- focused Coping and Performance
}

\begin{abstract}
Self-efficacy influences self-regulatory cognition and behaviour, including the way we approach and cope with problems and how we perform tasks. In this paper I examined the construct of self-efficacy and the strongly related variables of coping and performance to better understand how self-efficacy works at a fundamental level. I briefly reviewed some key concepts, measures and methods used in the study of selfefficacy, commenting on potentially important and understudied differences in coping styles that may influence self-efficacy. Specifically, problem-focused coping was the main coping strategy in the literature that had a positive correlation with both self-efficacy and performance. Lastly, I present some ideas for future research toward more understanding of the development of self-efficacy and its contributing factors.
\end{abstract}

Keywords: self-efficacy, active coping, passive coping, emotion-focused coping, problem-focused coping, performance

\section{Introduction}

Self-efficacy was defined by Bandura (1997) as the level of confidence an individual has of being able to perform a specific task successfully. The motivation to keep going and aim for a specific result is influenced by the individual's perceived self-efficacy for the task. Self-efficacy is a very important aspect of human cognition and survival because it shapes who a person becomes by what they believe they can do and what they go on to achieve. Right from a young age, parents, caregivers and teachers lay a foundational influence of expectations and abilities that children use as guidelines to evaluate themselves across contexts all the way to adulthood (Bandura, Barbaranelli, Vittorio \& Pastorelli, 2001; Parajes, 2005). 


\section{Developing Self-efficacy}

According to Bandura et al. (2001), children's perceived self-efficacy toward academic achievements and career choice can be partly related to parents and teachers' influence. Bandura and colleagues conducted a longitudinal study with middle school children based on the threefactor structure of perceived academic, social and self-regulatory efficacy. The researchers also considered parental and teacher influence, socioeconomic situation and profession of the parents. The findings supported the hypothesis that children do have a higher sense of self-efficacy for careers based on their perceived capabilities than for other careers. Bandura's team was also able to connect parental influence on children's self-efficacy to particular career choices. The children with higher than lower self-efficacy did go on to achieve academic excellence and increase their efficacy towards their occupation of choice. Pajares (2005) found support for Bandura and colleagues' (2001) findings, but added that children with high expectations due to their high selfefficacy react more negatively to a lower than expected performance compared to children with low self-efficacy.

Bandura's Social Cognitive Theory (SCT; 1989) provided a broader explanation as to how self-efficacy may have come into existence. According to this theory, human development is enhanced by engaging in detailed interaction with the environment and social circumstances. This process involves gathering self-relevant information through various reinforcing situational cues informing the self about what kind of activities to engage in and what not to engage in (Bandura, 1989). For example, a violent versus friendly face on a stranger may prompt avoidant versus approaching behaviour in the self. Repeated instances of successful avoidances versus interactions with others may instigate the analysis of self-knowledge, self-efficacy, or level of confidence from successes versus failures, and consequential self-regulatory actions (e.g., future avoidances or interactions based on cues and accumulated self-knowledge). Whenever interactions are rewarding, self-efficacy comes into play, boosting sense of capability, and encouraging people to engage in future, potentially more challenging interactions (Bandura, 1989). Based on this theory and supporting evidence, it is likely that social interactions enhance self-efficacy by increasing self-knowledge and facilitating self-related information processing needed for survival.

\subsection{Measuring Self-efficacy}

Measurements have been created to quantify the amount of self-efficacy individuals perceive in specific situations. A popular measure is Schwarzer \& Jerusalem's (1995) General Self-Efficacy Scale (GSE) designed for the general population. The GSE provides a broad view on how individuals perceive their ability to perform well in various situations and is used to predict the sense of control individuals perceive having in more specific and challenging situations.

The GSE's design is useful because it takes real-life contexts and individual differences into account to an extent. These types of considerations make sense in the context of SCT because Bandura (1989) explained that self-efficacy is a personal attribute developed solely by an individual to fit into one's own perceived future, which helps one in using self-regulatory capabilities to influence one's motivations and actions.

\subsection{Perceived Self-efficacy}

The amount of self-efficacy people perceive correlates positively with their previous performances and drives them to exude the confidence that influences the production of another 
good performance (Holzberger et al., 2013; Valiante \& Morris, 2013). Self-efficacy is built by analyzing the available skills an individual has to accomplish a task successfully and if the perception supports a successful outcome of the task, self-efficacy is high. Self-efficacy also seems to determine where, when and by how much these acquired skills would be used in order to achieve the perceived success (Pajares, 2005). This concept of self-efficacy from past studies and this relationship with self-regulation toward performance is what brings me to ask the question, what might be some contributing factors to this relationship, and how might these factors affect actual performance on tasks?

\section{Coping and Self-efficacy}

When an individual is faced with a problem, self-efficacy comes into play and instigates a particular coping strategy that matches with the level of the perceived self-efficacy of the individual (Carver et al., 1989). High self-efficacy has been associated with active coping (e.g., problem-solving, information seeking) and low self-efficacy with passive coping (e.g., avoidance, distraction). The most commonly reported active coping strategy used by individuals with perceived high self-efficacy is problem-focused coping (Carver et al., 1989; Shen, 2009; Hsieh et al. 2012). Problem-focused coping deals with a direct approach to solving the problem without making use of any external support apart from the acquired skills needed to solve the problem (Shen, 2009). With high self-efficacy, an individual believes that they do have the appropriate skills to successfully carry out a task or perform well with little to no external reliance or assistance (Pajares, 2005; Hsieh et al., 2012).

\subsection{Measuring Coping}

Carver et al. (1989) developed the COPE scale that assessed coping and categorized the different response styles of individuals into various kinds of coping. The researchers conducted three related studies. The first study was to develop the 13-item COPE scale questionnaire that measured coping styles, and the second study aimed to correlate the scale with personality types to see which personality types fitted with the different coping strategies. Some of the coping strategies assessed includes, active coping, planning, acceptance, and denial. Thirdly, Carver and colleagues validated the COPE scale and tested the hypothesis for the relationship between coping styles and situation specific coping responses.

Results showed that type-A personality (hard-driving, persistent) individuals used active coping but also engaged in emotion-focused coping by displaying strong emotions in stressful situations. The results showed that, in-line with previous theories and research, different situations sometimes warrant different coping techniques. A one-size-fits-all approach does not apply to using active coping, because some situations do not need direct solutions. Therefore, sometimes one needs an active strategy that involves some emotional or laid back approaches (e.g., going for a walk, expressing feelings, or socializing) in-order to relieve the accompanying stress of a situation, but not necessarily warrant a direct problem-solving approach.

\section{Performance, Coping and Self-efficacy}

Hsieh et al. (2012) conducted their research on the relationship between test anxiety and final grades, personal control, self-efficacy, self-regulation, coping strategies and goal orientation as predictors of final grades among undergraduate engineering students. Two structural models emerged; the first model involved a collection of self-efficacy, self-regulation, personal control, test anxiety and midterm grades as predictors of final grades. The alternative structural model 
was used to examine how the variables influence each other and findings showed that test anxiety, personal control and midterm grade had a positive relationship with self-efficacy. Hsieh et al. (2012) also found that students who experienced lower test anxiety (a type of self-efficacy) performed well and engaged in more active coping strategies than those who experienced higher test anxiety.

\section{Suggestions for Future Research}

Another way to investigate the usefulness of self-efficacy and the impact it has on performance could be to use the three-factor structure (Bandura et al., 2001) of perceived academic, social and self-regulatory efficacy, as well as factors such as parental and teacher influence, socioeconomic situation and profession of the parents, in a longitudinal study to examine these relationships throughout childhood to adulthood.

A future longitudinal study could explore the development and modification of selfefficacy throughout an individual's life. The longitudinal nature of the study would help researchers track the improvements made from childhood to adulthood on self-efficacy and could investigate the life choices made as well as explore the agents of changes that might have contributed to a diversion in any of the contributing factors involved in development and use of self-efficacy.

Regarding measurement of self-efficacy, Bandura (2006) did offer a guide for constructing self-efficacy scales, but a measure that applies specifically to children should be created to better understand how much influence parents, caregivers, social interaction, culture and environment have on children's efficacy at different times during development. If there is a threshold or critical age for development of optimal self-efficacy, understanding this more through longitudinal studies making use of adaptable measures could shed light on this and related processes.

Longitudinal studies may help clarify the development and processes involved in selfefficacy, but experimental manipulations should be undertaken to investigate the more precise nature of the relationships between self-efficacy, coping strategies, and performance considering individual differences and contexts throughout a longitudinal time frame.

\section{Conclusion}

Those with high self-efficacy use active coping strategies that make use of direct problem-solving and stress-relieving techniques (Carver et. al., 1989; Cicognani et al. 2009; Shen, 2009; Hsieh et al., 2012). Likewise, the ability to reduce stress correlates positively with both high self-efficacy and active coping strategies. Although active coping might seem very effective, it is not always the best strategy depending on contextual and individual differences. People with high self-efficacy may be able to adapt to situations that require other, non-direct coping strategies to tackle the stress better than those with low self-efficacy. Although this is a preliminary and exploratory investigation into these relationships, a quick search of psychology databases shows that more research would be helpful to examine the nature of the relationship between an individual's self-efficacy, the coping strategies used within different situations and cultural contexts, and the impact these factors have on performance.

\section{References}

Bandura, A. (1997). Self-efficacy: The exercise of control. New York: Freeman.

Bandura, A. (1989). Social cognitive theory. In R. Vasta (Ed.), Annals of child development. Vol. 6. (pp. 1-60). Greenwich, CT: JAI Press. 
Bandura, A. (2006). Guide for constructing self-efficacy scales. Self-efficacy Beliefs of Adolescents, 5 (307-337).

Bandura, A., Barbaranelli, C., Caprara, G., V., \& Pastorelli, C., (2001). Self-efficacy beliefs as shapers of children's aspirations and career trajectories. Child Development, 72(1), 187-206.

Carver, C., S., Weintraub, J., K., \& Scheier, M., F., (1989). Assessing coping strategies: A theoretically based approach. Journal of Personality and Social Psychology, 56(2), 267-283.

Cicognani, E., Pietrantoni, L., Palestini, L., \& Prati, G., (2009). Emergency workers’ quality of life: The protective role of sense of community, efficacy beliefs and coping strategies. Social Indices Resource, 94, 449-463.

Holzberger, D., Philipp, A., \& Kunter, M., (2013). How teachers' self-efficacy is related to instructional quality: A longitudinal analysis. Journal of Educational Psychology, 105(3), 774-786.

Hsieh, P., Sullivan, J., R., Sass, D., A., \& Guerra, N., S., (2012). Undergraduate engineering students’ beliefs, coping strategies, and academic performance: An evaluation of the theoretical models. The Journal of Experimental Education, 80(2), 196-218.

Pajares, F., (2005). Self-efficacy during childhood and adolescence: Implications for teachers and parents. Self-Efficacy Beliefs of Adolescents, 339-367. Retrieved April 1, 2014 from http://sites.education.uky.edu/motivation/files/2013/08/18464-Self-

Efficacy_During_Childhood_and_Adolescence-Implications_for_Teachers_and_Parents.pdf

Prati, G., Pietrantoni, L., \& Cicognani, E., (2010). Self-efficacy moderates the relationship between stress appraisal and quality of life among rescue workers. Anxiety Stress Coping, 23(4), 463-470.

Shen, Y., E., (2009). Relationships between self-efficacy, social support and stress coping strategies in Chinese primary and secondary school teachers. Stress and Health, 25, 129-138.

Schwarzer, R., \& Jerusalem, M. (1995). Generalized Self-Efficacy scale. In J. Weinman, S. Wright, \& M. Johnston, Measures in Health Psychology: A user's portfolio. (pp. 35-37). Windsor, UK: NFERNELSON.

Valiante, G., \& Morris, D., B., (2013). The sources and maintenance of professional golfer's self-efficacy beliefs. The Sport Psychologist, 27, 130-142. 